\title{
O TRABALHO COM RELATOS DE EXPERIÊNCIA NA FORMAÇÃO INICIAL: POR QUE É “MUITO IMPORTANTE OUVIR OS EDUCADORES DA ESCOLA PÚBLICA"?
}

\author{
Marcos Garcia Neira ${ }^{\mathrm{i}}$
}

\begin{abstract}
Resumo: Os relatos de experiência elaborados por professores, que afirmam colocar o currículo cultural da Educação Física em ação, substancializam os conhecimentos produzidos durante o fazer educacional. Esses registros foram tomados como os principais recursos didáticos da disciplina Metodologia do Ensino de Educação Física, componente curricular obrigatório de um curso de Licenciatura em Pedagogia de uma Instituição de Ensino Superior situada na capital paulista. Neste texto, promovemos um diálogo entre o percurso transcorrido e as análises das narrativas docentes elaboradas pelos licenciandos e licenciandas à medida em que se apropriavam dos referenciais epistemológicos e didático-metodológicos da Educação Física cultural. Dessa experiência extraímos duas aprendizagens importantes: os saberes elaborados pelos professores em atuação são bem recebidos quando incorporados ao currículo universitário e essa incorporação confere legitimidade não só aos conteúdos abordados como também à escola como espaço de produção de conhecimentos.
\end{abstract}

Palavras-chave: Formação de professores; Educação Física; Currículo.

\section{WORKING WITH EXPERIENCE REPORTS IN INITIAL TRAINING: WHY IS IT "VERY IMPORTANT TO HEAR PUBLIC SCHOOL EDUCATORS"?}

\begin{abstract}
The experience reports produced by teachers who claim to put the Physical Education cultural curriculum into action substantiate the knowledge produced during the educational activity. These records were taken as the main didactic resources of the discipline Physical Education Teaching Methodology, a mandatory curricular component of a Pedagogy Degree course at a Higher Education Institution located in the capital of São Paulo. In this text, we promote a dialogue between the elapsed path and the analysis of the teaching narratives prepared by the undergraduate and graduate students as they appropriated the epistemological and didacticmethodological references of cultural Physical Education. From this experience, we extracted two important learnings: the knowledge elaborated by the professors in action is well received when incorporated into the university curriculum and this incorporation gives legitimacy not only to the contents covered, but also to the school as a space for the production of knowledge.
\end{abstract}

Keywords: Teacher training; Physical Education; Curriculum.

\section{Introdução}

A lida escolar cotidiana exige não somente a mobilização e ressignificação de conceitos extraídos dos campos teóricos de referência. Esse processo acaba gerando um tipo de conhecimento bem específico. Sem reduzi-lo a mero domínio de um saber fazer baseado em teorias implícitas, o conhecimento docente está imbricado em relações sociais, haja vista a 
inseparabilidade entre prática pedagógica e atuação política. “O conhecimento que o professor ou professora produz não brota do ato pedagógico, é construído lenta e cuidadosamente através da avaliação criteriosa dos efeitos das ações didáticas emaranhadas em suas próprias circunstâncias" (NEIRA, 2019, p. 13).

Embora as pesquisas acadêmicas tratem o assunto como fato consumado, a inclusão dos saberes docentes nos cursos de licenciatura ainda é visto com ressalvas. Muitos consideram que os professores e professoras em atuação pouco têm a dizer sobre o que fazem, mergulhados que estão numa miríade de problemas e dificuldades e termina num fazer absolutamente divorciado da teoria. Para quem pensa dessa forma, a escola fracassa porque os educadores são mal formados e rejeitam por completo aqueles conhecimentos científicos que explicam a realidade e oferecem as balizas necessárias para vencer os desafios concretos.

No sentido contrário, os saberes produzidos pelos professores e professoras, consubstanciados em relatos orais, escritos ou em vídeos foram transformados em recursos didáticos da disciplina de Metodologia do Ensino de Educação Física, componente curricular obrigatório do curso de Licenciatura em Pedagogia de uma universidade pública paulista. A experiência pedagógica foi vivenciada durante o segundo semestre de 2019, por duas turmas com aproximadamente 60 pessoas matriculadas em cada.

A concepção de ensino abordada na disciplina é conhecida como Educação Física cultural, culturalmente orientada ou, simplesmente, currículo cultural. Em linhas gerais, essa perspectiva busca apoiar-se nas teorias pós-críticas do currículo (SILVA, 2015) para tematizar as práticas corporais (brincadeiras, danças, lutas, esportes e ginásticas), questionar os marcadores sociais que as perpassam e empreender uma ação política a favor das diferenças por meio do reconhecimento das linguagens corporais dos grupos minoritários.

Engajando professor e alunos na luta pela transformação social, a proposta prestigia, desde o planejamento, procedimentos democráticos para a definição dos temas de estudo e organização das situações didáticas, promove a reflexão crítica da cultura corporal vivencial disponível na comunidade para, em seguida, aprofundá-la e ampliá-la mediante o diálogo com outras representações e outras manifestações corporais. Não se trata simplesmente de substituir as práticas corporais hegemônicas (voleibol, handebol, basquetebol e futsal) por outras, nem tampouco de "mudar o jeito de ensinar", mas sim de propiciar a vivência, ressignificação, leitura da prática corporal, aprofundamento e ampliação de um repertório mais amplo, o que inclui também o trabalho pedagógico com os saberes da capoeira, maracatu, parkour, frevo, danças circulares, rodas cantadas etc. (NEIRA, 2011). 
Essa vertente é investigada há tempos pelo Grupo de Pesquisas em Educação Física escolar da Faculdade de Educação da Universidade de São Paulo, o GPEF, cujos participantes cultivam, desde 2006, o hábito de produzir relatos de suas experiências. No entender de Suárez (2008), os relatos de experiência revelam uma parcela importante do saber pedagógico construído e reconstruído ao longo da vida profissional em meio à multiplicidade de situações e reflexões. Tomando contato com esses documentos, é possível compreender boa parte das trajetórias percorridas por seus autores, as concepções que influenciam sua docência, as certezas e dúvidas que os mobilizam, as ideologias que perpassam suas convicções pedagógicas e também suas inquietações, desejos e realizações. A leitura e análise desses materiais permite conhecer uma visão da educação escolar bastante distinta daquela comumente veiculada nos meios de comunicação ou oficializada através dos informes das avaliações padronizadas. O que salta aos olhos é o currículo em ação narrado justamente por aqueles que planejam, desenvolvem e avaliam o processo. Materializando o testemunho de quem põe as mãos na massa, transformam-se em produções suscetíveis à investigação e crítica, provocando a revisão do olhar sobre o fazer pedagógico e os saberes docentes. (NEIRA, 2018)

Em estudo recente, Borges (2019) explica que na última década do século passado a pedagogia brasileira deu vazão à adoção de registros diários como subsídio para reordenar o planejamento e, além disso, a reflexão do fazer docente. Guardadas as devidas especificidades, o intuito do registro no currículo cultural da Educação Física mantém alguma semelhança com esse propósito, mas não se restringe a ele. Tomado como situação didática, o registro consiste em recurso fundamental para analisar a trajetória percorrida e os efeitos gerados nos estudantes, mas também como dispositivo indutor à produção de conhecimentos sobre a prática pedagógica (MÜLLER, 2016). Uma vez concluída a tematização de uma brincadeira, dança, luta, esporte ou ginástica, o ato de documentar o percurso apoiando-se nas anotações, fotografias, filmagens e nos materiais produzidos pelos participantes, possibilita ao professor um pensar sobre, sendo-lhe possível olhar o trabalho pedagógico concluído com a distância necessária para dele abstrair aprendizagens fundamentais a respeito da docência (NEIRA, 2018).

O registro materializado de diferentes formas é indispensável para que os professores interpretem suas ações e as ações dos alunos e possam seguir o caminho pensado ou modificá-lo, se necessário. No caminhar, caso emerja alguma questão relevante para o estudo, ainda que provoque certo desequilíbrio, o professor reorganiza as atividades de ensino buscando outros elementos, reconfigurando assim sua ação, dando novos contornos ao desenho das aprendizagens. (ESCUDERO, 2011, p. 161) 
Além do registro sistemático das atividades de ensino, muitos docentes que colocam o currículo cultural da Educação Física em ação também produzem relatos escritos ou fílmicos de suas experiências pedagógicas. Tais produções dão visibilidade aos conhecimentos produzidos pelos próprios docentes e consubstanciam-se em materiais potentes para autoformação ou formação inicial e contínua (NEIRA, 2018). Uma vez publicados no site ${ }^{\mathrm{ii}}$ do GPEF e nas redes sociais ${ }^{\mathrm{iii}}$, essas narrativas elaboradas por professores e professoras que afirmam realizar a Educação Física cultural podem ser acessadas por qualquer pessoa com acesso à internet.

Desse conjunto de documentos, aqueles publicados em 2017 e 2018 foram analisados no transcurso da disciplina Metodologia de Ensino de Educação Física. Ademais, em alguns casos e a depender da disponibilidade do autor ou autora, puderam apresentar suas experiências oralmente em sala de aula e conversar a respeito com os licenciandos e licenciandas.

\section{A experiência formativa em diálogo com as produções docentes}

Os objetivos da disciplina Metodologia do Ensino de Educação Física estão disponíveis na página eletrônica da instituição, mesmo assim foram reapresentados no site especialmente elaborado para a disciplina. Cabe destacar os seguintes: relacionar as concepções de ensino de Educação Física à a produção das identidades dos sujeitos; contextualizar a Educação Física cultural e reconhecer seus campos de inspiração; compreender as noções de tematização, problematização e desconstrução adotadas pela Educação Física cultural; justificar a importância dos princípios ético-políticos da Educação Física cultural; caracterizar as situações didáticas da Educação Física cultural e reconhecer a singularidade dos conteúdos da Educação Física cultural. Finalmente, como se trata de uma disciplina com carga horária de estágio acoplada, essa atividade formativa teve como objetivo planejar, desenvolver e avaliar intervenções didáticas pautadas na Educação Física cultural.

O trabalho com relatos orais teve início na segunda semana letiva, quando organizadas em pequenos grupos, as turmas foram convocadas a abstrair as identidades projetadas por uma experiência narrada. Para tanto, foram convidados os professores autores do relato. Havia certa preocupação em propiciar o quanto antes a interação com educadores que afirmavam colocar em prática a proposta, dado que as conversas iniciais com os licenciandos e licenciandas revelaram que suas experiências com a Educação Física enquanto estudantes da Educação Básica basearam- 
se em referenciais psicobiológicos, consequentemente, distantes do atual estágio dos conhecimentos da área.

Transmutando as performances dos corpos: rebeldias $e$ transgressões educacionais foi uma prática desenvolvida no $3^{\circ}$ ano do Ensino Fundamental I da Rede Municipal de Ensino de São Paulo, na região do Capão Redondo, no ano de 2018, pelos professores de Educação Física Flávio Nunes dos Santos Jr. e o professor regente do $3^{\circ}$ ano $\mathrm{C}$, Vitor Quaresma. A oportunidade do trabalho conjunto aconteceu por ocasião da Festa Junina da escola, todos os professores foram convocados a treinarem seus alunos e alunas numa "dança tradicional" para ser apresentada para a comunidade e famílias no dia da festa. Os professores aqui apresentados não sentiram que aquelas músicas e as danças tivessem qualquer relação com a identidade dos alunos. Durante o ano o objetivo da escola era o controle dos corpos e a alfabetização e na festa junina vinha uma proposta de treinamento que não respeitava as crianças, esses corpos, que antes estavam acorrentados, deveriam agora ser treinados para uma atividade mecânica, de adestramento e que não tinha nada que se relacionasse com a sua cultura. Os professores Vitor e Flávio, a partir da concepção ampliada do respeito às culturas não dominantes na escola e rompendo com uma visão tradicional de dança, começam a conversar com os alunos para entender qual música que ouvem fora da escola, a ideia era tentar desenvolver uma proposta de dança dentro do espaço escolar que respeitasse a cultura da região e principalmente a cultura negra e periférica. Nas conversas com os alunos começa a aparecer o funk como um ritmo que fazia parte do cotidiano, mesmo que muitas famílias resistissem ou proibissem os filhos de vivenciá-las. Sem dúvida nenhuma os professores enfrentaram resistências da escola, das famílias e dos próprios alunos, que muitas vezes reproduziam os preconceitos em relação ao ritmo e dança que nasce das periferias e principalmente dos negros. (Grupo $\mathrm{X}^{\mathrm{iv}}$ )

Após a leitura da bibliografia indicada e discussão em sala de aula a partir dos argumentos apresentados pelas teorias pós-críticas do currículo (multiculturalismo crítico, estudos culturais, teoria queer, pós-modernismo, pós-estruturalismo, estudos de gênero e pós-colonialismo), as turmas foram incentivadas a analisar relatos de experiência previamente selecionados, impressos e distribuídos em sala de aula, buscando identificar o(s) campo(s) teórico(s) que possivelmente inspiraram seus autores. A mesma atividade foi proposta por mais duas semanas devido à complexidade das teorias estudadas, aos questionamentos dos licenciandos e licenciandas e ao tempo necessário para analisar os relatos de experiência disponibilizados. Os fragmentos abaixo foram extraídos das análises mediante o confronto com a teorização pós-crítica do currículo:

Esteve presente nas falas e nas provocações feitas pelo professor o entendimento de que os sentidos atribuídos ao jogo de taco fazem parte de uma construção cultural e social, sobretudo nos momentos de aprofundamento do tema (tanto por conta dos vídeos e textos trazidos por ele, quanto pelos momentos de fala das crianças), pois entendeu que naquele momento a turma estava representada e representando um certo poder cultural. Atribuo esses momentos, aos estudos culturais e ao pós-colonialismo. (DSN ${ }^{\mathrm{v}}$, grifos nossos $)^{\mathrm{vi}}$

Revista Interinstitucional Artes de Educar. Rio de Janeiro, V. 7, N. 1 - pág. 116-131 janeiro-abril de 2021: "Pedagogias Vitais: Corpo, Desejo e Educação" DOI: 10.12957/riae.2021.51619 
A partir dessas concepções que as problematizações sobre "é coisa de índio", de "baiano" vão sendo descontruídas e questionadas, evidenciando as relações étnico raciais e as proposições dos estudos culturais. No entanto, não só elas são objeto de análise e reflexão. Os questionamentos de gênero sobre a participação masculina ou os comentários indicando que meninos que vestem saia são "bichas", ao serem problematizadas, "em vez de contorná-los, os professores os transformam em desafios, incorporando-os ao estudo", ativam outros campos teóricos, como a teoria queer, além de favorecem a compreensão de que os discursos que diminuem, maltratam, humilham, menosprezam e desqualificam são elaborados e disseminados. (JASS, grifos nossos) ${ }^{\mathrm{vii}}$

Sendo assim, a leitura do relato de experiência possibilitou o exercício de identificar quais campos teóricos possam ter inspirado o professor. Se pensarmos no multiculturalismo crítico ou intercultural, este partilha do raciocínio de que a produção cultural de alguns grupos é menosprezada em contrapartida a de outros. Dessa forma, busca-se compreender como tais visões são construídas e quais relações de poder exercem forças sobre o patrimônio cultural. A escolha pelo sumô pode ter sido influenciada por essa necessidade de entender as diferentes maneiras de ver o mundo e perceber as mais sutis relações de poder presentes em discursos corporais que produzem o predomínio de culturas de grupos dominantes. Em um currículo multiculturalista "a diferença, mais do que tolerada ou respeitada, é colocada permanentemente em questão". Assim, no relato de experiência foi colocado em questão os corpos dos lutadores de sumô que, bem diferentes do que é validado pelas mídias e culturas dominantes, põe em xeque algumas percepções preconceituosas. Além disso, permite refletir sobre esses corpos não de maneira a desenvolver tolerância ou respeito, mas sim de perceber que estes também estão no jogo de poder. (LAK, grifos nossos) ) $^{\text {viii }}$

Como se observa, a realização da análise requer algum nível de compreensão das teorias que inspiram os professores e professoras a $\operatorname{artistarem}^{\mathrm{ix}}$ o currículo cultural da Educação Física. Guardando alguma fidelidade com esses campos teóricos, sobretudo com o pós-estruturalismo, muitas leituras de um mesmo texto são possíveis. Logo, ao se debruçar sobre um mesmo relato de experiência, os licenciandos e licenciandas interpretaram-no de formas distintas, daí a solicitação para que justifiquem seus posicionamentos. Vejamos os seguintes casos:

Um ponto importante, que gostaria de ressaltar antes de prosseguir a análise de como se deu o desenvolvimento da temática, é justamente na escolha desse tema, pois o que vemos repetidamente durante as aula de educação física é o ensino de práticas corporais hegemônicas como o futebol e vôlei e suas técnicas, então vejo que abordar a luta e ainda por cima problematizar a caracterização que a torna marginalizada (a violência) também é um ato que vai contrário a isso, podendo até na minha visão conter princípios do multiculturalismo crítico. (IFM, grifos $\operatorname{nossos})^{\mathrm{x}}$

Apesar de não estar presente no texto, o jiu-jítsu tem como uma de suas origens os samurais que se não tivessem com espada ou lança teriam que usar um método de luta sem armas e apesar dessa luta ser algo presente no mundo todo, sua origem é pouco falada e valorizada, por isso, acredito que quando tematizam essas lutas estamos usando a teoria pós crítica do pós-colonialismo que amplia o significado 
das relações de povos diferentes e menos valorizados, analisando a narrativa desses povos. (MTLT, grifos nossos) ${ }^{6}$

Para discutir as noções de tematização, problematização e desconstrução que caracterizam a perspectiva em estudo, as turmas assistiram a dois vídeos que relatam experiências pedagógicas: O desafio da garrafa na Educação Física escolar ${ }^{x i}$ e Kung Fu: arte marcial chinesa no Júlio ${ }^{x i i}$. A primeira desenvolvida junto às turmas do terceiro ano de uma escola pública municipal de Guarulhos, a segunda em um Centro Integrado de Educação de Jovens e Adultos e a terceira em uma escola municipal paulistana com as turmas do quinto ano.

\begin{abstract}
No primeiro vídeo, gostaríamos de destacar a relação da atividade para além do corpo e da atividade corporal dentro da instituição escolar. A correlação com as fake news e a produção de verdades tornou a primeira tematização (desafio da garrafa) um embasamento para que novas tematizações a partir, novamente, da realidade das crianças. Entendemos que essa forma de abordagem modificou a forma do olhar fragmentado para uma ampliação das perspectivas dos(as) educandos(as) remetendo mais diretamente a ideia dos rizomas.

No segundo vídeo, ressaltamos que a atividade parte do universo cultural vivencial, uma vez que a tematização do Kung fu parte muito mais do universo aquém do cotidiano imediato das crianças, mas sem deixar de contextualizá-lo de acordo com o conhecimento do grupo como um todo. Durante nossa discussão no grupo, concordamos que as práticas foram melhor estruturadas. (Grupo Y)
\end{abstract}

Ao fim e ao cabo, após comentar as análises elaboradas, as turmas perceberam que, na ótica de Santos (2016), a tematização compreende a totalidade do trabalho realizado com o objetivo de propiciar aos estudantes condições para realizar uma leitura mais qualificada da prática corporal; a problematização implica em desnaturalizar por meio da indagação formas de compreender e realizar a prática corporal e a desconstrução, conforme Neves (2018), significa compreender quais elementos intervieram e como operam as relações de poder para produzir uma determinada representação sobre a brincadeira, dança, luta, esporte ou ginástica e seus participantes.

$\mathrm{Na}$ continuidade do curso, as sugestões de leitura abarcaram artigos que descrevem pesquisas focalizadas nos princípios ético-políticos da Educação Física cultural. As turmas conheceram a noção de agenciamento nos termos colocados por Deleuze e Parnet (1998) como “despertar o desejo de". Neira (2019) explica que os professores culturalmente orientados são agenciados pelos seguintes princípios ético-políticos: reconhecer a cultura corporal da comunidade, articular o tema com o projeto político-pedagógico da escola, descolonizar o currículo, promover a justiça curricular, favorecer a enunciação dos saberes discentes e ancorar 
socialmente os conhecimentos. A partir deles, foram convidadas a analisar relatos de experiência buscando inferir os princípios que possivelmente agenciaram seus autores, quer seja na definição da prática corporal a ser tematizada, ou na organização das situações didáticas, justificando seus posicionamentos.

Agenciado pelos princípios ético-políticos, no relato foi possível identificar os seguintes princípios: reconhecimento da cultura corporal dos estudantes: houve o reconhecimento da prática corporal vivida pelos alunos no deslocamento da sala de aula para o local onde vivenciavam a aula de educação física, sempre correndo. Articulação com o projeto da escola: levou em consideração o projeto político pedagógico, Gestão das aprendizagens e das relações interpessoais nos espaços tempo da escola, além de levar em conta a participação em um projeto chamado Territorialidades. Há nessa iniciativa uma resistência ao Currículo da Cidade, mas não foi mais explicada durante o relato. Justiça curricular: partindo da ideia de romper com as exclusividades de valores que intensificam noções de superioridade/inferioridade, analiso que a proposta contemplou outra vivência da corrida na qual o desempenho físico não era tão importante, assim como na brincadeira de aventura que o coletivo importa para o cumprimento da prova.

Descolonização do currículo: o conceito de descolonização do currículo como "a tematização de práticas corporais dos grupos subalternizados e que têm estado ausentes do currículo" não foi identificada no relato. Evitar o daltonismo cultural: a partir desse conceito, identifico que a desconstrução da ideia dos corpos aptos, ligados ao ser magro, e os inaptos, ligados ao ser gordo em nossa sociedade, ou seja, formas de representações hegemônicas da vivência dessa corporalidade. Também identifico esse princípio, ao problematizar o conceito de diversão, e competição ligada a questões econômicas. Também presente quando o professor propôs a vivência da corrida eletrônica. Ancoragem social dos conhecimentos: o professor possibilitou a análise sócio-histórica e política da prática corporal através das atividades de pesquisa e discussão que buscaram desnaturalizar as concepções trazidas sobre o correr, proporcionando assim, uma relação da prática dentro do seu contexto social, além de oportunizar o conhecimento de territórios do entorno para o exercício da prática. (AF, grifos nossos) $)^{\text {xiii }}$

O professor reconhece o patrimônio cultural corporal da comunidade ao desenvolver um trabalho educativo que valoriza as raízes culturais da comunidade na qual a escola está inserida e da cultura brasileira, de acordo com o universo cultural dos(as) alunos(as), tematizando-as e tratando-as como um conteúdo. Assim, os conhecimentos que os educandos acessam através das conversas com amigos, observações do cotidiano e das mídias foram meios que constituíram como um referencial importante para que o professor lesse e traduzisse a cultura dos seus alunos e suas práticas corporais. Na articulação com o projeto político pedagógico da escola, o docente extraiu no repertório cultural corporal dos(as) alunos(as), a dança, como um tema cultural cujo estudo articula com os objetivos institucionais definidos coletivamente e tem como base as metas da escola. Além disso, em suas práticas o professor descoloniza o currículo ao ampliar as oportunidades de acesso a vários significados e proporcionar uma participação mais equitativa, promovendo um diálogo entre culturas, convivência e partilha coletiva com o diferente, questionando a existência de culturas particulares autênticas. $\mathrm{Na}$ rejeição ao daltonismo cultural, devido a existência de diferentes culturas no espaço escolar, o professor 
buscou ampliar as práticas corporais dos(as) alunos, reivindicando atividades que permitissem lidar com a heterogeneidade, além disso, na ancoragem social do conhecimento, sem almejar a padronização dos efeitos formativos, propôs ações didáticas voltadas para a valorização das diferenças e dos saberes dos estudantes ao diversificar as suas práticas pedagógicas. (GYAC, grifos nossos) ${ }^{\mathrm{xiv}}$

Em se tratando de um curso de metodologia do ensino, o tema "situações didáticas da Educação Física cultural” era aguardado com alguma ansiedade, pois, afinal, no decorrer dos encontros, várias vezes se discutiu a tessitura das atividades de ensino, concebida como escritacurrículo pela bibliografia do curso.

Em relação a tematização das brincadeiras africanas, percebe-se que está de acordo com a discussão de Santos (2016), principalmente por se tratar de algo que parte das vivências já exploradas pela escola ao longo dos anos mais recentes, o que também é conduzido pela perspectiva rizomática de conhecimento, que busca enfatizar experiências diversas obtidas não só em contexto escolar, mas dentro das adquiridas em outros locais e partilhadas entre os colegas. As crianças da EMEI Nelson Mandela tiveram como proposta investigar a origem de algumas brincadeiras comuns a essas realidades, à essas vivências, o que frisa ainda mais a noção do rizoma proposta por Santos (2016). Esse constante questionamento, esse caráter rizomático, também está relacionado ao modo como as vivências curriculares são escritas, denominado como escrita-currículo. Bonetto (2016) define como uma escrita de "[...] caráter aberto, não linear, nem tampouco baseado em sequências didáticas." E continua: [...] é a produção de experiências curriculares menos rígidas, inspiradas na participação ativa e crítica de professores e alunos que assumem a condição de "escritores" da experiência curricular. É uma relação de reciprocidade, de constante construçãoreconstrução. Podem, como preferimos dizer na perspectiva pós-estruturalista, produzir diferentes experiências curriculares, onde o novo, o criativo, o imprevisto, é desejado e não evitado. Desse modo, ao pensar nas modificações afirmadas por Gonçalves e Duarte (s/d), conforme redigido no relato, pensa-se justamente em uma escrita-currículo, cujas propostas são sempre repensadas, ressignificadas, dialogadas e (re)escritas pelos sujeitos das experiências. (TCRS, grifos nossos) $)^{\mathrm{xv}}$

Observa-se que os licenciandos e licenciandas se apropriaram das situações didáticas que caracterizam a Educação Física cultural à medida em que adquiriram familiaridade com os relatos de experiências. Não seria necessário nomeá-las, por assim dizer, pois a lida semanal com as narrativas docentes permitia o acesso ao modo de fazer dos professores culturalmente orientados. Sempre alternando os documentos analisados, os licenciandos e licenciandas identificaram com certa facilidade as situações didáticas de mapeamento, leitura da prática corporal, ressignificação, aprofundamento, ampliação, registro e avaliação. 
A princípio, realizaram o mapeamento, trazendo à tona os conhecimentos e significados que os alunos detinham acerca das danças. Antes, ponderaram a presença quase que exclusiva das brincadeiras no planejamento da disciplina, optando, portanto, por outra prática corporal. Afirmam que: "Analisando o que as crianças tinham dito sobre o dançar, o local de origem de suas famílias, as práticas de dança que conheciam e as localidades onde se performavam, elegemos a ciranda como nosso objeto de estudo" (p. 2) Após isso, realizaram a leitura de imagens e vídeos, com o objetivo de introduzir o tema, já que os estudantes não conheciam a ciranda. Nesse momento, a professora de Artes tomou conhecimento da atividade, atraindo-se pela dinâmica. Ocorreu, então, a primeira vivência, onde os estudantes conheceram e cantaram a música Cirandeiro, composta por Edu Lobo; valeram-se da voz para ecoar a letra e das palmas e batidas nas carteiras, realizando a percussão. Num outro momento, o grupo continuou vivenciando a dança; alguns se responsabilizaram pela cantoria, e outros, pela formação da roda, realizando os passos. Feito isso, as crianças fizeram uma leitura de suas próprias experiências, analisando o que havia sido interessante, e os pontos que poderiam ser trabalhados. Julgaram que seria importante reorganizar a roda, de modo a deixá-la mais acolhedora, intensificando a necessidade de reconhecer o outro como condição mais que necessária para realização da dança. Ao tomar contato com a matéria produzida pelo programa Fantástico, aprofundam suas percepções sobre a ciranda, descobrindo os sentimentos e valores relacionados à roda, e conhecem a importante personalidade, Lia de Itamaracá. Também constatam informações sobre o contexto de invenção da ciranda, suas características e seus praticantes. Concomitante a isso, outra experiência tomava as turmas das séries iniciais: as crianças dos $1^{\circ}, 2^{\circ}$ e $3^{\circ}$ anos, manifestavam um fervor performático, que lembrava mais o funk do que a ciranda. Diante disso, os educadores se atentaram às vontades e rejeições dos alunos em relação à proposta didática, optando por também tematizarem o funk. Pode-se dizer que esses momentos se enquadram em avaliação - do andamento da atividade, da postura dos alunos e dos próprios professores - e mapeamento - com a identificação do próximo passo da tematização. Refletindo sobre os apontamentos dos estudantes, professores e professora decidiram problematizar esse corpo que se movimenta ao ritmo do funk. E não pararam nisso, propuseram também uma ampliação por meio do cruzamento entre ciranda e funk, onde as crianças do Ensino Fundamental I e as turmas do $6^{\circ}$ ano, puderam compartilhar seus conhecimentos. Acredito que nessa ocasião, em que as turmas se reúnem, a ressignificação dos saberes e das práticas se evidencia - embora tenha ocorrido também em outras situações. O registro também se mostrou como momento de leitura e interpretação, daquilo que acabara de ocorrer, e também de avaliação, sobre todo o processo. (SYRTF, grifos nossos) $)^{\mathrm{xvi}}$

Considerando a especificidade dos conteúdos abordados nas aulas, após uma intensa discussão das noções de conhecimento e cultura corporal que perpassam a Educação Física cultural (NUNES, 2018), as turmas retomaram os relatos de experiência e buscaram neles identificar os conteúdos acessados pelos estudantes. Os resultados da atividade indicam não só a compreensão desses conceitos, como dão vazão ao principal aspecto que distingue essa proposta das demais. Basta verificar que, naqueles documentos que relatam trabalhos com a mesma prática corporal, os conhecimentos postos em circulação se diversificaram. 
Todas as vivências e as situações didáticas propostas bem como as pesquisas realizadas ampliaram a discussão sobre racismo e preconceito a outras situações como o preconceito contra o estrangeiro (xenofobia), os gays (homofobia), as mulheres que jogam futebol (sexismo) ou contra os pobres ou trabalhadores (classe social). O professor Leandro Souza também aproveitou para discutir as regras do futebol, com novos textos e vídeos, para que percebessem que nem sempre esse esporte foi jogado com as mesmas regras, que portanto toda a prática corporal cultural é também uma construção histórico social, que surgiu como resultado de disputas que inevitavelmente silenciam ou excluem determinados grupos. Também foi possível perceber que o mesmo ocorre com as regras para o uso ou não da piscina de um prédio ou dos elevadores sociais, como os alunos tinham revelado no início do mapeamento das práticas culturais. As vivências na quadra possibilitavam que os alunos e alunas se apropriassem de modos de jogar diferentes, se apropriassem do jogo, criando e adaptando as regras que viam nos vídeos. Vivenciar formas diferentes do jogo por diferentes grupos, culturalmente diferentes dos alunos e alunas permitiu que o próprio jogo fosse ressignificado, chegando até a se recriar outras formas de se jogar o futebol. (VMBTC) (Vvii $^{\mathrm{x}}$

A avaliação atribuída ao projeto pelxs professorxs a partir dos registros foi que analisando em perspectiva, conseguiram abordar o futebol de muitas maneiras e que foram atravessados por vários conhecimentos sobre a prática corporal. Durante as vivências as crianças trouxeram questões variadas que enfatizaram gênero, com falas de que futebol é somente para meninos e sobre pessoas com deficiência, com falas relativas a um padrão de corpo para quem joga futebol. Segundo xs autores do relato "Passamos a ver a prática corporal de outra maneira, principalmente, os modos de jogar, considerando a participação de todas as pessoas." Por fim, as crianças decidiram que no último jogo que fizeram dentro deste projeto, que derivou dos conhecimentos acessados por elas, que deveria haver equipe de arbitragem, equipe médica, banco de reservas, técnico e torcida. Elas próprias escolheram seus papéis com liberdade para trocar de funções durante a partida, além disso superaram a hipótese que existia no discurso da turma, no começo do projeto, sobre padronização dos corpos no futebol, assim, realizaram um jogo aonde tanto meninas como meninos puderam participar e também Giovana uma criança com deficiência. $(\mathrm{CSB})^{\mathrm{x} \text { viii }}$

Se considerarmos as noções de tematização e escrita-currículo discutidas em sala de aula com base nos trabalhos de Santos (2016) e Bonetto (2016), respectivamente, e que atravessam a concepção de conhecimento da perspectiva cultural Educação Física, é interessante perceber que os licenciandos e licenciandas identificaram seu caráter rizomático.

O relato tem o conhecimento trabalhado como um tecido rizomático, em que os pontos de um rizoma podem e devem se conectar a quaisquer outros pontos, promovendo a heterogeneidade. Sendo o conhecimento algo que não tem um exato começo e um fim, que tudo que se aprende está interligado de forma intrínseca. Nas atividades em que o professor do relato apresentou, em nenhum momento havia algo pontual para que trabalhava, todos os conhecimentos trabalhados estavam interligados e que em alguns momentos tinha que se lembrar dos primeiros encontros para que pudesse fazendo sentido para aquela vivência do momento. (GCR, grifo nosso) ${ }^{\mathrm{xix}}$ 
Pensando em uma produção rizomática do conhecimento no processo da tematização, de maneira que a Educação Física Cultural potencializa o contato com diversos saberes, os conhecimentos acessados pelas crianças durante a tematização do carimbó foram: a história e origem do carimbó; a história dos negros e indígenas no Brasil; a cultura indígena; a cultura da região Norte do Brasil; dança de roda; figurino usado em diferentes manifestações do carimbó; diferentes manifestações do carimbó (diferentes espaços e organizações); danças tradicionais como reprodutoras dos papéis sociais. (HOPF, grifo nosso) ${ }^{\mathrm{xx}}$

O professor Marcos Ribeiro Neves, que realizou seu trabalho "a gente corre pra que?" traz à tona pontos importantíssimos que demonstram sua preocupação com fazer uma Educação Física que valorize as diferenças, trazendo um tema muito corriqueiro, porém pouco problematizado, que é a corrida. Todas as crianças, dentro de suas capacidades, correm. Seja para se deslocarem, para brincarem, ou até mesmo sem motivo pré-estabelecido. $\mathrm{O}$ professor se atenta a esta prática corporal, o que é conhecemos como mapeamento na teoria da educação física cultural. Para então, após o mapeamento, poder de maneira rizomática tematizar a corrida. Por meio de vivências corporais demonstra como estas práticas da corrida estão presentes no cotidiano daquelas crianças. Em seguida, o professor entrou em contato com uma de suas colegas de trabalho e conseguiu trazer ao colégio um treinador de corrida, para que pudesse apresentar', junto a toda sua equipe, os artefatos utilizados na corrida. Ampliando e dando outra significação dessa mesma manifestação cultural. Desta maneira, criou vínculo com outros colegas da escola também. (MPB, grifo nosso) $)^{\mathrm{xxi}}$

Se retomarmos os objetivos da disciplina Metodologia do Ensino de Educação Física, verificaremos que dentre eles consta "planejar, desenvolver e avaliar intervenções didáticas pautadas na perspectiva cultura". Esse objetivo foi alcançado mediante a realização de estágios em escolas públicas e privadas, seja na Educação Infantil ou no Ensino Fundamental nas modalidades regular ou Educação de Jovens e Adultos. Fiéis à proposta, após a conclusão das experiências, as licenciandas e licenciandos foram estimulados a produzir relatos de experiência escritos ou em formato de vídeo.

A variedade das temáticas abordadas e a qualidade das narrativas evidencia os efeitos positivos do percurso formativo que buscou entretecer os conhecimentos produzidos pelos professores em atuação com os saberes científicos, sem desconsiderar o repertório dos próprios estagiários e estagiárias: Polícia e ladrão e a dança do dragão (LO e TCSR); Brincadeiras indígenas e africanas no território escolar (ACMS e GSA); Brasil, o país do futebol (DQES e VMBTC); Vivências escolares no samba de roda (AJSP); A gente quer dançar (AF); Ela dança, eu (não) danço? (ACV); Em cima da árvore posso alcançar o céu? (AMRN); Brincadeiras africanas na escola (CML); Tematizando a amarelinha (CSB); Tematizando as brincadeiras de antigamente (DAS); O corpo que dança: tiktok na escola (DN e HF); Meia volta e não mover: por que não pode brincar? (DTC); Vamos jogar futebol... mas, e as meninas? Elas não sabem jogar! 
(DPA); Brincadeiras perderam seu valor para os jogos eletrônicos? (GCR); Quem ficar mais quieto ganha! Tematizando a brincadeira da mímica na EMEI Vanda Coelho (GSL); Intervindo nas práticas corporais durante os momento de parque (GRM); Tematizando o beyblade (GMT); Educomunicação, práticas corporais e linguagens artística? (IMP); Brincadeira da escola e brincadeira de casa (ILJ); Das aulas de Língua Portuguesa às práticas corporais (JASS); As danças das crianças (JMR); Tipos de pega-pega (JNS); Quintal do João Menino (KPS); Tematizando as danças de origem africana (LAN); Futebol x cordas: brincadeiras de meninos $e$ meninas (LAB); Tematizando a cultura popular nas danças infantis (LAO); Punhos na mesa e o bate copos: o ritmo e a corporalidade (LFOS); As danças dos estudantes (MAN); Tempo passado, tempo vivido, tempo presente: os brinquedos na EJA (MCFS); Vivenciando brincadeiras africanas na Educação Infantil (MISS e RCS); Brincadeiras de corda (MVNP e MTO); Tematizando o pião e o beyblade na Educação Infantil (PMG); As torcidas enquanto prática corporal (RSS); $O$ combinado não sai caro (RAM); Baby Shark é música/dança de bebê? (SYRTF e VMLC); Brincadeiras no berçário (TCO); Tematizando brinquedos (TMM); Danças circulares (VA e FML); Não há vencedores, o importante é competir. Será mesmo? (HRS); Professora, vai ter jogo? (RLB); Dança e brincadeira, uma necessidade esquecida no ensino fundamental (MRG); Mixagens artísticas (LS); Ba-ba-lu - os jogos de mãos (HS); Capoeira (GFP); Brincadeira de elástico (MHPB); Então a gente também pode dançar? (MFC); Aerofacebol (RMQ) e Brincando na Educação Infantil (RGF).

Sem perder a condição de autores e autoras, não foram poucos os participantes da disciplina que na condição de estagiários e estagiárias buscaram inspiração nos vários relatos de experiência que acessaram para planejar as próprias intervenções didáticas. Isso aconteceu na medida em que se deram conta de que as opções dos professores e professoras mais experientes não podem simplesmente ser reproduzidas. Cada escola e cada turma constituem contextos absolutamente distintos. Por isso, ao desejarem levar a cabo a prática pedagógica culturalmente orientada, tiveram que fazê-lo com os pés no chão, elaborando objetivos, definindo a prática corporal tematizada e criando e recriando situações didáticas específicas.

Encerrando as atividades da disciplina Metodologia do Ensino de Educação Física, as licenciandas e licenciandos foram instados a responder as seguintes questões disponíveis em formulário eletrônico: o que você modificaria na organização e desenvolvimento da disciplina? E o que você manteria na organização e desenvolvimento da disciplina?

Algumas respostas fizeram referência direta ao trabalho com os relatos de experiência: "os textos teóricos dão embasamento a análise das experiências e ponto a ponto, permitindo Revista Interinstitucional Artes de Educar. Rio de Janeiro, V. 7, N. 1 - pág. 116-131 janeiro-abril de 2021: "Pedagogias Vitais: Corpo, Desejo e Educação" DOI: 10.12957/riae.2021.51619 


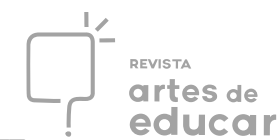

assimilar a lógica da Educação Física cultural"; "No começo do curso, algo parecido com a última aula, onde nós analisamos os vídeos das lutas. Para mim me fez entender melhor como que é feito as vivências"; "Se possível, colocaria mais relatos de experiências para serem apresentados."; "Sugiro ampliar de 2 para 3 dias as datas reservadas para apresentação dos trabalhos de estágio no findar da disciplina." "Eu gostei do formato como foi proposta a disciplina."; "As atividades e os encontros com outros estudantes que já realizaram a disciplina."; "Manteria a apresentação e análise dos trabalhos desenvolvidos pelos colegas professores."; "Manteria as diversas possibilidades e formatos para o trabalho final (vídeo, relato de experiência, fotos...). Permite um registro mais efetivo e significativo para quem realizou o estágio.”; "Manteria apresentação dos relatos de experiências."; "Manteria a proposta do estágio obrigatório."; "Achei muito bom as explicações e as discussões em torno de exemplos práticos. Também, o modo como são feitas as atividades contribuem para leitura. Achei o curso muito bom!"; "Manteria as leituras dos relatos."; "Manteria relatos e vídeos das práticas em Educação Física cultural. Muito importante ouvir educadores da escola pública!".

\section{Considerações finais}

É fato que o desenvolvimento da disciplina atribuiu um lugar de destaque ao confronto dos relatos de experiência com os referenciais epistemológicos e didático-metodológicos da perspectiva cultural da Educação Física, o que permitiu converter os saberes produzidos pelos professores e professoras em atuação em conhecimentos trabalhados no curso.

A compreensão gradativa da proposta foi revelada semanalmente mediante as análises das atividades realizadas pelos licenciandos e licenciandas. Essa constatação autoriza dizer que os saberes elaborados pelos professores e professoras em atuação foram bem recebidos quando incorporados ao currículo universitário.

A opção de propor a análise de relatos de experiência vislumbrou mais uma alternativa para a formação inicial de professores. A lida com as narrativas docentes diminui a distância entre a universidade e a escola ao aproximar licenciandos e licenciandas do ensino que efetivamente acontece. Através da leitura dos relatos, percebem-se professores e professoras estudiosos, comprometidos com a construção de uma sociedade menos desigual e atentos às realidades em que atuam. Receberam a proposta de apresentar suas experiências aos futuros colegas de braços abertos e não se furtaram a oferecer-lhes o que têm de melhor: o seu fazer pedagógico. Em sua 


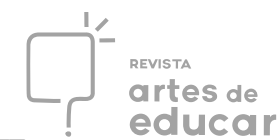

generosidade, abriram as portões das escolas e os deixaram entrar, ler suas histórias, sentir suas frustrações e alegrias, acompanhar os momentos bons e os mais difíceis, aprendendo sempre. Em meio ao trabalho com os relatos, percebemos que nossa docência se enriquece, o que fez surgir a vontade de documentá-la para que outros formadores ou formadoras de professores possam desfrutar das mesmas sensações.

\section{REFERENNCIAS}

BONETTO, P. X. R. A “escrita-currículo” da perspectiva cultural de Educação Física: entre aproximações, diferenciações, laissez-faire e fórmula. 2016. 238f. Dissertação (Mestrado em Educação) - Universidade de São Paulo, Faculdade de Educação, São Paulo, 2016.

BORGES, C. C. O. Governo, verdade, subjetividade: uma análise do currículo cultural da Educação Física. 2019. 181 f. Tese (Doutorado em Educação) - Faculdade de Educação, Universidade de São Paulo, São Paulo, 2019.

CORAZZA, S. M. Pesquisa-ensino: o "hífen" da ligação necessária na formação docente.

Araucárias: Revista do Mestrado em Educação da FACIPAL, Palmas, PR, v. 1, n. 1, p. 7-16, 2002.

DELEUZE, G.; PARNET, C. Diálogos. São Paulo: Escuta, 1998.

NEIRA, M. G. Educação Física. São Paulo: Blucher, 2011.

NEIRA, M. G. Relatos de experiência com o currículo cultural da Educação Física: formando professores e professoras no "chão da escola". In: NEIRA, Marcos Garcia. (Org.). Educação Física cultural: relatos de experiência. Jundiaí: Paco, 2018. p. 9-19.

NEIRA, M. G. Educação Física cultural: inspiração e prática pedagógica. $2^{\text {a }}$ Ed. Jundiaí: Paco, 2019.

NEVES, M. R. O currículo cultural da Educação Física em ação: efeitos nas representações culturais dos estudantes sobre as práticas corporais e seus representantes. 2018. 198 f. Dissertação (Mestrado em Educação) - Universidade de São Paulo, Faculdade de Educação, São Paulo, 2018.

NUNES, H. C. B. O jogo da identidade e diferença no currículo cultural da Educação Física. 2018. 157 f. Tese (Doutorado em Educação) - Universidade de São Paulo, Faculdade de Educação, São Paulo, 2018.

SANTOS, I. L. A tematização e a problematização no currículo cultural da Educação Física. 2016. 246 f. Tese (Doutorado em Educação) - Universidade de São Paulo, Faculdade de Educação, São Paulo, 2016. 
SILVA, T. T. Documentos de identidade: uma introdução às teorias do currículo. Belo Horizonte: Autêntica, 2015.

SUÁREZ, D. H. La tradición crítica en educación y reconstrucción de la pedagogía. In: ELISALDE, R.; AMPUDIA, M. (comp.) Movimientos sociales y educación: teoría e historia de la educación popular en Argentina y América Latina. Buenos Libros, Buenos Aires, 2008. p. 193-214.

SUÁREZ, D. H. Relatos de experiencia, saber pedagógico y reconstrucción de la memoria escolar. Educação em Revista, Belo Horizonte, v. 27, n. 01, p. 387-416, abr. 2011.

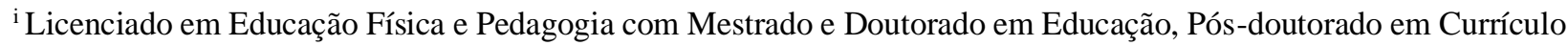
e Educação Física e Livre-Docência em Metodologia do Ensino de Educação Física. É Professor Titular da Faculdade de Educação da USP, onde atua nos cursos de graduação e pós-graduação, orienta pesquisas em nível de Iniciação Científica, Mestrado e Doutorado, supervisiona pesquisas de Pós-Doutorado e coordena o Grupo de Pesquisas em Educação Física escolar (www.gpef.fe.usp.br). Realiza investigações com o apoio da Fapesp e do CNPq, do qual é Bolsista de Produtividade em Pesquisa. Orcid - 0000-0003-1054-8224.
}

ii $\mathrm{O}$ site do GPEF - www.gpef.fe.usp.br - pode ser tomado como um arquivo de toda a produção do grupo: artigos, livros, capítulos de livros, vídeos e, principalmente, relatos de experiência.

${ }^{i i i}$ www.facebook.com/pesquisaef e www.youtube.com/gpeffeusp

iv Atividade realizada em grupos.

${ }^{v}$ Iniciais dos nomes dos estudantes autores das análises.

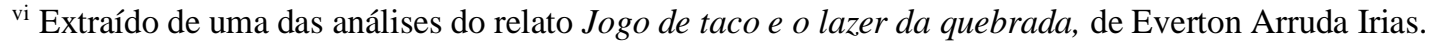

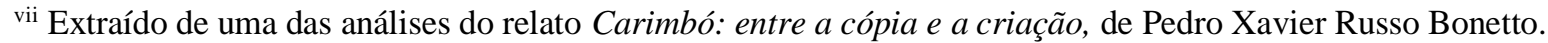

viii Extraído de uma das análises do relato Entre fritadas, assados e muito cheiro bom: um encontro com o sumô e seus corpos, de Felipe Nunes Quaresma.

ix Sandra Corazza (2002) cunhou o termo “artistagem”. Artistar é uma estética, uma ética e uma política a se inventar junto a uma educação que procura “[...] o não sabido, o não olhado, o não pensado, o não sentido, o não dito" (p. 14). A pesquisa, o trabalho do professor com seus orientandos e alunos, dá-se nas zonas fronteiriças, na penumbra da cultura, nas tocas mais estranhas da linguagem. Como em todo desenvolvimento de uma arte, artistar a educação implica entregar-se ao caos para extrair dali matérias para criações. Trata-se de "arriscar-se, assumir o risco da morte, que é estar viva/o, sem se considerar um produto acabado" (p. 15).

${ }^{x}$ Extraído de uma das análises do relato Se lutar é violência, por que a igreja do bairro ensina jiu-jitsu?, de Luiz Alberto dos Santos

${ }^{x i}$ Disponível em https://www.youtube.com/watch?v=M4BF2pUSIbY

xii Disponível em https://www.youtube.com/watch?v=IRJ_dJax_a4

xiii Extraído de uma das análises do relato A gente corre para quê?, de Marcos Ribeiro das Neves.

xiv Extraído de uma das análises do relato Carimbó: entre a cópia e a criação, de Pedro Xavier Russo Bonetto.

${ }^{\mathrm{xv}}$ Extraído de uma das análises do relato Tematizando as brincadeiras na EMEI Nelson Mandela, de Tathyana Gonçalves e Leonardo de Carvalho Duarte.

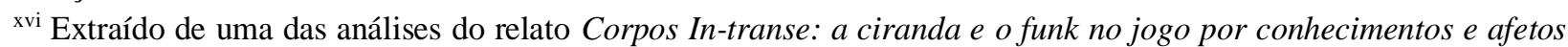
outros, de Ana Carolina Torres, Felipe Nunes Quaresma e Flávio Nunes Santos Júnior.

xvii Extraído de uma das análises do relato Futebol além das bananas, de Leandro Rodrigo Santos de Souza

xviii Extraído de uma das análises do relato GOOOLLLAAAÇCOOOOO! Tematizando o Futebol na EMEI Nelson Mandela, de Marina Basques Masella e Leonardo de Carvalho Duarte

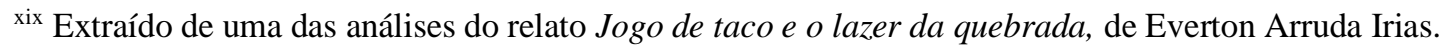

${ }^{\mathrm{xx}}$ Extraído de uma das análises do relato Carimbó: entre a cópia e a criação, de Pedro Xavier Russo Bonetto.

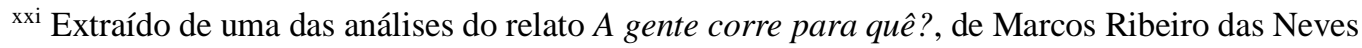

